\title{
UN MOTIVO LITERARIO A LA LUZ DE LA CELESTINA: DE LOS LIBROS DE CABALLERÍAS AL TEATRO ÁUREO
}

\author{
A LITERARY MOTIF IN THE LIGHT \\ OF LA CELESTINA: \\ FROM BOOKS OF CHIVALRY \\ TO GOLDEN AGE DRAMA
}

\author{
José Julio Martín Romero \\ Universidad de Jaén \\ jjmartin@ujaen.es
}

Resumen: El presente estudio determina la existencia de un motivo literario no detectado hasta ahora: el contratiempo peligroso de la cita secreta nocturna de los amantes. Demuestra que su origen se encuentra en la muerte de Calisto en La Celestina. Además, establece la estructura del motivo: la cita erótica secreta y nocturna, la aparición de personajes inoportunos y la lucha consecuente. Asimismo, analiza su aparición en diversos libros de caballerías, así como en el teatro áureo (El caballero de Olmedo de Lope de Vega). Este artículo, por tanto, muestra que la influencia de los libros de caballerías va más allá de lo que normalmente se acepta y alcanza diversos géneros literarios.

Palabras clave: La Celestina; libros de caballerías; teatro del Siglo de

Oro; motivos literarios; Lope de Vega.

Abstract: This article determines the existence of an as yet undetected literary motif: the dangerous setbacks to the lovers' secret nocturnal meeting. This work shows that the motif can be traced back to the death of Calisto in La Celestina and establishes its structure: the lovers' secret nocturnal rendez-vous, the arrival of characters who disturb the meeting and the subsequent struggle. It also analyses the appearance of this motif in books of chivalry, as well as in Golden Age drama (The knight of Olmedo by Lope de Vega). Consequently, the influence of books of chivalry is shown to go beyond what it is usually believed, making itself felt in many literary genres.

Keywords: La Celestina; chivalry books; Golden Age drama; literary motifs; Lope de Vega.

Recepción: 11 de diciembre de 2017; aceptación: 20 de julio de 2018. 
Los distintos tipos de influencia de La Celestina en los libros de caballerías han sido puestos de relieve desde hace tiempo*. Ya Lida de Malkiel (1962, p. 650) comentó las similitudes entre el consejo en Amadís que la hija del conde de Selandia recibe de su doncella y el que Lucrecia da a Melibea; efectivamente, las semejanzas son notables: "Señora, aquel coraçón que tuvistes para errar, aquél tened agora para os dar remedio" (Rodríguez de Montalvo 1991, t. 1, p. 628); "Ten esfuerço para sofrir la pena, pues toviste osadía para el placer” (Rojas 2001, p. 589). Aunque la investigadora admitía que era "materia de conjetura", consideraba sorprendentemente que "La Celestina fue antes la fuente que la imitación" $(i d$.$) . Con más acierto, Lida de Mal-$ kiel comentó la inclusión de un fragmento del acto XIV de $L a$ Celestina en la traducción francesa del sexto libro amadisiano de Herberay des Essarts y se preguntaba si se debió a que éste pudo "haber percibido la huella de La Celestina en el Amadís de Rodríguez de Montalvo" (1962, p. 651, n. 31).

Otros estudiosos han continuado indicando recuerdos celestinescos en los libros de caballerías, como Sales Dasí (2000) en Lisuarte de Grecia; Campos García Rojas (2013) en Primaleón; González Gonzalo (2005, pp. xiii-xv) en la primera parte de Clarián de Landanís o Guijarro Ceballos (2001 y 2002, p. 262) en la segunda.

Para comprender el influjo de esta obra, en principio tan alejada del universo propuesto por los libros de caballerías, es necesario partir del carácter experimentador del género caballeresco, un género heterogéneo en constante variación y abierto a cualquier tipo de influencias; no olvidemos, por poner tan sólo un ejemplo, que se dejó influir, entre otros, por la lírica garcilasiana (Martín Romero 2004).

Además, seguramente la frontera entre lo idealista y lo realista no fue tan claramente percibida en la época como tiende a pensarse. Por un lado, La Celestina también entraba en el peligroso terreno de la ficción, tan criticado por los moralistas (Sarmatti 1996). Y, por otro, como afirma Marín Pina, "los libros de caballerías están más apegados de lo que se piensa al mundo cotidiano, a la experiencia de los lectores, y la realidad se cuela

* Este artículo se enmarca dentro de las actividades del proyecto I+D+i DHuMAR. Digital Humanities, Middle Ages $\mathcal{E}$ Renaissance. 1. Poetry. 2. Translation (MINECO, FFI2013-44286-P) y se ha realizado en el seno del equipo de investigación EI_HUM6_2017 (IP:J.J. Martín Romero) de la Universidad de Jaén. 
por mil rendijas" (2008, p. 108). Esto no sólo sucede en aquellos libros de caballerías considerados realistas -como los analizados por Guijarro Ceballos (1999) o Lucía Megías (2000)-, sino que no son infrecuentes en títulos pertenecientes al resto de paradigmas de los que habla este último investigador. Los estudios de Sales Dasí y Lucía Megías (2002, 2005, 2007, 2009) han revelado que el universo social en los libros de caballerías es mucho más amplio de lo que la historiografía venía aceptando y abarca tipos bien diversos que en ocasiones se acercaban a lo propuesto en obras de corte tan distinto como La Celestina.

El texto de Rojas ha de entenderse como un rechazo del reflejo de las relaciones amorosas en la ficción sentimental (Lacarra 1989 y Severin 1984), de manera que guarda con este género una clara relación. Ello explica que lo celestinesco fuera fundiéndose con el género sentimental en obras como Penitencia de amor de Pedro Manuel Jiménez de Urrea (Gómez 1990), texto que recibe abiertamente tanto la influencia de las obras de San Pedro y Juan de Flores, como la de Fernando de Rojas. Por tanto, los amores en La Celestina también se relacionan con el modo como aparecían reflejados en los textos caballerescos y artúricos, a los que tanto debe, a su vez, la novela sentimental (Spinelli 1983-84; Sharrer 1984; Deyermond 1993; Blay Manzanera 1998; Brandenberger 2012) ${ }^{1}$. Ello puede demostrar que, si La Celestina desenmascara lo que se oculta tras las palabras corteses de los amantes, si logra mostrar de forma descarnada los deseos reales que escondían los comportamientos de los amantes "perfectos" de la literatura considerada "idealista", quizá haya que pensar que esas palabras y comportamientos supuestamente idealizados eran fácilmente decodificables por los receptores coetáneos, que sabían descifrar sin problemas la verdadera intención que yacía en esas expresiones y modales cortesanos.

En los libros de caballerías, por lo demás, se observan formas cada vez más humanas, más realistas de presentar las relaciones amorosas (ya muy carnales desde el paradigma amadisiano, no hay que olvidar). La inclusión de elementos eróticos cada vez menos idealizados se vincula con la humanización de personajes, circunstancias y realidades en los libros de caballerías, como revela una simple comparación entre Amadís y algunos de sus descendientes, como Florisel (Martín Romero 2010).

1 Siguen siendo interesantes las reflexiones de Beysterveldt (1982) sobre la contextura coetánea de La Celestina. 
Esa distancia resulta aún mayor si se compara la perfección de Amadís con el comportamiento de Palmerín, protagonista del primer libro de caballerías ajeno al ciclo amadisiano (Martín Romero 2014 y 2015).

No hay que olvidar el hecho de que Feliciano de Silva fue, como indicó Sales Dasí (2001), un "aventajado continuador" celestinesco; ello influyó en su aprendizaje de escritura dramática; como indicó Cravens (2000, p. 67), "se echa de ver en esto que Silva, como autor que era de Segunda Celestina (1535), ya se inclinaba tanto a lo teatral como a lo narrativo".

Por último, se ha señalado que el texto de Rojas se vio influido por un texto caballeresco, el Tirant lo Blanc, como ha demostrado pormenorizadamente Beltrán Llavador (1988, 1990, 1990a, 1991 y 1994). Este investigador analiza determinados paralelismos en momentos como el enamoramiento, la consumación de las relaciones y la muerte del caballero, así como las similitudes entre el personaje de Plaerdemavida con Lucrecia y la propia Celestina en el texto de Rojas. Si la novela catalana fue efectivamente fuente de La Celestina, habría que replantearse los límites entre géneros diversos, así como el modo en que se recibían ${ }^{2}$.

Se podría objetar que Tirant lo Blanc resulta claramente distinto de las obras castellanas del género y que eso permitió que influyera en una obra como La Celestina. Ciertamente, Tirant, compuesto en el siglo Xv, presenta características más cercanas al texto de Rojas que Amadís; pero no hay que olvidar que éste es reescritura coetánea -pero, al fin y al cabo, reescritura- de un texto muy anterior. Los motivos que en realidad llevaron a Martín de Riquer (1973, pp. 277-278) a considerar el Tirant como "novela caballeresca" frente a Amadís, denominado "libro de caballerías", justificarían que buena parte del corpus castellano fuera considerado igualmente "novela", porque, efectivamente, las derivaciones quinientistas de la tradición amadisiana presentan en no pocas ocasiones ciertas inclusiones de lo cotidiano, una ruptura con el maniqueísmo y una forma bien alejada del supuesto idealismo que se supone propio de este tipo de literatura, todo lo cual la acerca de alguna manera al texto de Rojas ${ }^{3}$.

${ }^{2}$ Se ha de recordar el interés de Rojas por los libros de caballerías, a juzgar por los que conservaba en su biblioteca (INFANTES 1989).

${ }_{3}^{3}$ Martín de Riquer marca las características de Tirant, que coinciden con las de un grupo determinado de la producción románica (con textos como Jehan de Saintré, por ejemplo). Se trata de una visión generalizada 
No se debe olvidar lo confuso del adjetivo "realista" aplicado a la literatura. La Celestina acoge la cotidianeidad, presenta personajes cuya humanidad resulta, como indicó Cervantes, abrumadora, pero dudo que buscara un reflejo fiel de la realidad. La erudición o el estilo retóricamente adornado de muchos de sus parlamentos evidencian prurito literario más que fidelidad a formas reales de expresión. No obstante, el carácter eminentemente literario, ficticio, del texto no puede considerarse un demérito ni en el caso de La Celestina ni en el de los libros de caballerías.

De cualquier modo, resulta innegable la influencia celestinesca en las obras caballerescas, la cual se detecta fundamentalmente en dos aspectos interrelacionados de manera ocasional: 1) la figura de la hechicera y/o alcahueta y 2) las relaciones eróticas.

En cuanto al segundo de los aspectos, el texto de Rojas hubo de servir de modelo -junto con los textos caballerescos- a los autores de libros de caballerías a la hora de narrar encuentros amorosos, esto es, sexuales, entre sus personajes. Es cierto que, como se ha indicado, se trata en ocasiones de lugares comunes procedentes de la tradición folclórica o literaria (Campos García Rojas 2013), pero resulta extraño pensar que el recuerdo de La Celestina no esté en la raíz de la aparición de ciertos elementos como los estudiados por los investigadores arriba aludidos.

En algunos de los estudios antes mencionados, se analiza la posible influencia celestinesca en el encuentro secreto de los amantes. Efectivamente, la cita amorosa nocturna y clandestina de los amantes con elementos como la huerta, las rejas, las escalas y los muros no son infrecuentes. Cervantes, lector privilegiado de estos textos, lo señaló en al menos dos ocasiones en el Quijote, una en el capítulo 21 de la Primera parte:

Y aquella noche se despedirá de su señora la infanta por las rejas de un jardín, que cae en el aposento donde ella duerme, por las cuales ya otras muchas veces la había fablado, siendo medianera y sabidora de todo una doncella de quien la infanta mucho se

en Europa que baña de cotidianeidad y de ciertos detalles realistas la vida caballeresca. Pero muchos de los libros de caballerías castellanos ofrecen también esa visión menos idealizada (sobre todo si se compara con el paradigma amadisiano) de la caballería. De cualquier modo, quizá el error sea buscar en Amadís (una obra que, aunque reescrita, procede del siglo xIv) características propias de una época posterior. 
fiaba. Suspirará él, desmayaráse ella, traerá agua la doncella, acuitaráse mucho porque viene la mañana, y no querría que fuesen descubiertos, por la honra de su señora. Finalmente, la infanta volverá en sí y dará sus blancas manos por la reja al caballero, el cual se las besará mil y mil veces y se las bañará en lágrimas (2001, I, 21, pp. 203-204).

Y, de nuevo, en el capítulo 44 de la Segunda parte, si bien de forma más esquemática. Tales citas cervantinas revelan que esto se percibía como un lugar común caballeresco. En nota al primero de estos pasajes, Diego Clemencín recordó ciertos momentos en los que en los libros de caballerías se encontraba este tipo de entrevistas amorosas: el capítulo 14 de Amadís de Gaula; el cap. 58 de Lisuarte de Grecia; el cap. 5 y el 35 de Palmerín de Olivia; el cap. 135 de la parte II de Palmerín de Inglaterra; los caps. 47 y 73 del segundo libro de El Caballero de la Cruz, y, finalmente, el cap. 21 del libro V de Florambel de Lucea (Clemencín 2001, pp. 1206-1207, n. 64).

No obstante, aquí me interesa señalar un desarrollo específico de este tipo de episodios: no sólo el hecho de que haya encuentros eróticos clandestinos y nocturnos, sino que de dicho encuentro surjan ciertos riesgos que hacen suponer un recuerdo celestinesco: la muerte de Calisto. Considero que se trata de un motivo, es decir, una unidad recurrente de contenido que, además, en este caso, se construye mediante la combinación de otros motivos simples (el encuentro de los amantes, los riesgos de la cita amorosa); por tanto, se trata de lo que Bueno Serrano (2012, p. 90) ha denominado un "motivo sintagmático compuesto" 4 .

${ }^{4}$ Por tanto, no entenderé motivo como "unidad mínima de contenido". Utilizo los términos sintagmático y paradigmático tal como los definió Bueno Serrano (2012, p. 90): "En esta agrupación la mayor extensión del enunciado del motivo tendrá una mayor concreción (motivo sintagmático) mientras que a su menor longitud le corresponderá una menor concreción o, lo que es lo mismo, una mayor abstracción (motivo paradigmático)”. El análisis de motivos presenta una serie de problemas vinculada con el grado de abstracción y la forma de percepción de la materia narrativa. En este estudio, sin embargo, propongo un motivo compuesto con una serie de variantes concretas, "sintagmáticas", que, precisamente por su concreción y su recurrencia, resulta muy interesante y lo separa de los motivos simples que lo construyen, motivos simples que, de forma más abstracta (en grado paradigmático), pueden rastrearse en el folclore y en numerosas culturas. Sin embargo, con las variantes precisas (sintagmáticas) analizadas aquí se convierten en material de análisis relevante. Sobre los motivos caballerescos, 
Precisamente algunos estudiosos han analizado de forma individual casos en los que estos momentos han sido vistos como posible impronta celestinesca. Así ha sido puesto de relieve por Sales Dasí (2000) en un episodio de Lisuarte de Grecia y por González Gonzalo (2005) en otro del libro primero de Clarián de Landanis. En el caso de Lisuarte de Grecia, Sales Dasí, además de mencionar los rasgos celestinescos de la maga Alquifa (la figura de la hechicera/ alcahueta, el primero de los aspectos que indiqué anteriormente), comenta también la relación amorosa entre Lisuarte y Onoloria (el segundo de los aspectos); pues bien, Sales Dasí (2000) recuerda cómo en el capítulo 89 el héroe corre el riesgo de caer de la escalera apoyada en el muro cuando se queda obnubilado ante la hermosura de su amada, de forma que, "por un instante, Lisuarte está a punto de correr la misma suerte que Calisto”. Será la dama, Onoloria, quien lo salve agarrándolo por la garganta; este investigador considera que ambas situaciones, a pesar de las diferencias, "sí que manifiestan una gran afinidad".

En el caso de Clarián de Landanís, González Gonzalo (2005) no llega a afirmar una relación directa entre ambas obras, pero la considera una hipótesis posible; recuerda, por una parte, la figura de Celacunda, viuda vestida de negro que mediante su habilidad retórica convence a la dama de que acepte el amor del caballero y utiliza la magia, todo lo cual coincide con el retrato de Celestina (2002-2003 y 2005, p. xiv); por otra, además de ese recuerdo de la hechicera/ alcahueta, el estudioso señala ecos celestinescos en el capítulo 116. Este capítulo narra cómo, "una noche que él salía de hablar con su señora... siendo baxados por la pared de la gran huerta" (Velázquez del Castillo 2005, p. 354), Clarián se encuentra con dos hombres, don Palamís y su escudero. Aunque Clarián decide marcharse antes de ser descubierto, el otro va tras él para saber quién es; Palamís increpa a Clarián, quien logra identificar a su rival por la voz, pero, por no querer darse a conocer, comienza a combatir; finalmente, Clarián huye herido. Para González Gonzalo (2005, p. xiv), este lance tiene puntos en común con La Celesti$n a$ : más allá del encuentro amoroso y nocturno, se presenta el

Bueno Serrano 2007 y 2012; Cacho Blecua 2012; Garza Merino 1998 y Luna Mariscal 2007, 2008, 2010, 2010a y 2013. Para una discusión terminológica y un repaso bibliográfico sobre los diversos conceptos de motivo, cf. Martín Romero 2015c, pp. 9-11. 
riesgo de muerte (que resulta efectiva en el caso de Calisto) a causa de dichos amores furtivos. Así, los riesgos derivados de la cita clandestina y nocturna entre los amantes son vistos como posibles reminiscencias del texto de Rojas, lo que viene reforzado por otras similitudes ${ }^{5}$.

Por mi parte, analizaré otros episodios que evocan éste de Clarián de Landanis; pertenecen a Palmerín de Olivia (1511), a Belianís de Grecia (1547), de Jerónimo Fernández, y finalmente, a Olivante de Laura (1564), de Antonio de Torquemada. En todos ellos se observa una serie de rasgos básicos que se repite y que bien puede deberse a un recuerdo de La Celestina.

Como he indicado, la recurrencia de este tipo de episodios permite considerarlo un motivo compuesto. En mi opinión, su aparición fue propiciada por el texto celestinesco; el centro de este motivo es el encuentro clandestino, pero que va más allá del lugar común comentado por Cervantes para convertirse en una estructura más amplia que implica la aparición de personajes que perturban o impiden esa cita, lo que conlleva un cierto peligro para el caballero. Esto es, el motivo de la cita secreta nocturna y furtiva (con las variantes sintagmáticas del muro, la escala, las rejas, etc.) se une al de los riesgos derivados de dicho encuentro (con variantes sintagmáticas como la aparición de personajes inoportunos, el enfrentamiento, etc.). De alguna manera, este motivo -que podríamos definir como el contratiempo peligroso de la cita secreta nocturna de los amantes- ofrece la situación que Calisto tenía en mente cuando bajó apresuradamente por el muro.

Eso sucede, además de en el citado episodio de Clarián, en el capítulo 6 de Palmerín de Olivia (1511), que narra el intento de Florendos por raptar a su amada Griana, con su consentimien-

${ }^{5}$ No deja de ser significativo que Beltrán Llavador indicara como posible recuerdo de Tirant lo Blanc sobre La Celestina la muerte del caballero como resultado de haber consumado la relación sexual con su amada: "Las muertes de uno y otro, abundando en el sentido de la parodia, son caídas simbólicas, relacionadas con el acto amoroso. Tirant tropieza y cae repetidamente, y siempre a renglón seguido de cada uno de sus avances sentimentales" (1994, p. 175). Aunque evidentemente las circunstancias entre ambos textos son diferentes (y aquí los libros de caballerías castellanos, aun cuando no concluyan en muerte, se acercan más a la situación celestinesca), el vínculo entre relación sexual y caída (hasta la caída final, la muerte) resulta clara en ambos textos, como indica Beltrán Llavador. El episodio celestinesco, por tanto, recuerda a Tirant, un texto caballeresco, y, a su vez, fundamenta un motivo en los libros de caballerías castellanos. 
to. El amor de estos personajes - progenitores del héroe- tendrá obstáculos mayores que los que tuvieron que vencer Elisena y Perión en el modelo amadisiano (Martín Romero 2015 y 2016). De hecho, la amenaza (que se hará efectiva) de matrimonio de la dama con el otro pretendiente (Tarisio) estructura buena parte de la obra. El citado episodio narra cómo Florendos se acercó al lugar donde solía verse secretamente con su amada, pero, cuando se proponía subir al muro para encontrarse con ella, apareció su rival amoroso: "como llegó, quiso subir encima de la pared para tomar a su señora..., llegó Tarisio" (2004, p. 20). Se inicia una lucha entre ellos que, aunque evita el rapto, termina con Tarisio gravemente herido y con Florendos huido. Mientras tanto, Griana oye el estrépito de la batalla e intuye de qué se trata: "Griana, que en la huerta estava, oyó el ruido de las armas e los fuertes golpes que davan los cavalleros" (p. 21). El autor alude a la reacción anímica de la dama, que parece llevarla a la muerte: "Fue ella tan turbada que por poco no murió de pesar" (id.); de hecho, ella misma, como otra Melibea, afirma en estilo directo que ya no desea seguir viviendo: "Anda, ve -dixo Griana- que yo más quiero la muerte que la vida" $(i d$.$) .$ Los puntos en común con la escena celestinesca son evidentes: 1) el encuentro secreto; 2) el muro que ha de escalar el amante; 3) el peligro del caballero a causa de este encuentro y 4) la desesperación (la desperatio o deseo de morir) de la dama que, mientras que en el texto de Rojas se lleva a efecto, en el libro de caballerías no se realiza y se limita a su expresión verbal.

Por supuesto, también son notables las diferencias, pero ello no impide considerar que el trágico desenlace de los amores de Calisto y Melibea se mezclara en Palmerín de Olivia con los modelos amadisianos en la historia de amor clandestino que desemboca en la procreación del héroe. Además, en este punto Palmerín de Olivia, frente a la obra de Montalvo, presenta rasgos mucho más crudos y un héroe mucho más humano, con sus defectos y vicios. El autor de Palmerín de Olivia quiso desprender de los personajes y situaciones caballerescas la aureola idealizada y así devolverlos al ámbito de lo humano para presentarlos como individuos con sus intereses y egoísmos: ello coincide con la actitud de La Celestina, que se oponía a la literatura que idealizaba lo que en el texto de Rojas se consideraba pura lujuria y causa de estragos en los mancebos. Cierto es que el carácter moralizante del texto celestinesco está ausente en Palmerín, pero el proceso de humanización es común a 
ambas obras; todo lleva a pensar que su autor fusionó lo celestinesco con lo amadisiano.

Como he indicado, en Belianís de Grecia (1547) de Jerónimo Fernández puede leerse un episodio que coincide con la estructura del palmeriniano; también aquí encontramos una cita amorosa clandestina que se ve obstaculizada por la presencia de caballeros inoportunos con el riesgo consecuente para el amante. Así, Belianís, tras haber concertado encontrarse con su amada Florisbella de forma secreta, se acerca al postigo indicado a horas en las que, en principio, nadie debería estar allí. No obstante, dos caballeros se encuentran precisamente en las cercanías del mencionado postigo, lo que impide que el héroe pueda acercarse de manera oculta. Esto le fuerza a esperar bastante tiempo con el deseo de que se marchen, pero en vano; agotada su paciencia, se dirige a ellos, eso sí, cambiando la voz para evitar ser reconocido:

como junto a él llegasse, vio dos caualleros arrimados. Y començando a dar bueltas por la calle, esperando si acaso se quitarían, estuuo gran pieça, mas viendo que por ninguna manera hazían menzión de se apartar, estando tan enojado que con la gran passión quería rebentar, se llegó a ellos y demudando la voz, dixo:

-¿Qué es lo que atendéys aquí, caualleros, aora que ninguno parece por la ciudad? (Fernández 1997, t. 2, p. 84).

El tono no deja lugar a dudas del malhumor del héroe ante este contratiempo: los increpa de manera poco cortesana e incide en el hecho de que no es hora para frecuentar ese lugar, lo cual resulta cuando menos paradójico, pues él mismo está ahí y con intenciones poco ortodoxas; quizá por ello los "caualleros, no haziendo caso dél, se riyeron no curando por esso de se apartar de donde estauan" ( $i d$.).

Belianís, entonces, al verse obligado a actuar, "puso mano por su espada" $(i d$.$) , al igual que los dos caballeros, aunque$ inmediatamente decide retirarse para evitar ser conocido (el mismo motivo por el que había mudado su voz). No obstante, sus contrincantes lo persiguen y se inicia una lucha durísima, en la que el héroe logra desembarazarse de ellos hiriéndolos (a uno de ellos en la cabeza) y dejándolos por muertos, tras haber recibido algunas heridas de menor importancia ${ }^{6}$. Belia-

${ }^{6}$ En otras ocasiones, las heridas son mucho más graves, pero eso no le impedirá a Belianís continuar con sus hazañas. Sobre la importancia de las 
nís, como Florendos en Palmerín de Olivia, se enfrenta a un verdadero peligro (recordemos, tal como Calisto pensaba que le sucedería cuando bajó apresuradamente por el muro tras su encuentro con Melibea). El riesgo que Calisto imaginaba encontrar en la calle es el que se produce de forma efectiva en estos libros; éstos narran lo que tenía en la cabeza el personaje de Rojas cuando un tropiezo le hizo caer de la escalera y encontrar una muerte tanto más ridícula (y por ello tanto más ejemplarizante) cuanto que no había peligro alguno.

En Belianis, por tanto, encontramos la cita clandestina nocturna, así como la aparición de hombres a la hora y lugar señalados para dicho encuentro, obstáculo que desemboca en una lucha con el consecuente riesgo para el amante, a pesar de que, con la intención de no ser reconocido, intenta evitar el enfrentamiento, muda la voz e incluso se retira. De nuevo, el motivo del encuentro amoroso nocturno y secreto forma parte de un episodio mayor: un motivo compuesto en el que también aparece un claro riesgo para la vida del caballero, riesgo que se concreta en una lucha de espadas con quienes se encuentran en el lugar señalado para la cita erótica.

También en Olivante de Laura (1564) de Antonio de Torquemada se lee un episodio con una estructura similar a la analizada. En este libro se narra la desgraciada relación amorosa entre Theobaldo y Lupercia. La historia presenta rasgos claramente celestinescos en cuanto al carácter ilícito de su relación, así como a su trágico desenlace. Theobaldo, hijo del conde de Altaroca, cae rendido ante la belleza de Lupercia, una de las doncellas de la reina. El enamoramiento lleva al caballero a un estado que recuerda al de Calisto: "Theobaldo, no siendo en su poder la resistencia contra las poderosas fuerças del cruel amor, se enamoró fuertemente, tanto que, perdiendo todos los sentidos, los ocupava solamente en contemplar la gran hermosura de Lupercia" (1997, p. 433); es cierto que no deja de ser la forma frecuente de reflejar el enamoramiento -la enfermedad de amor o hereos- y que, en consecuencia, no resulta especialmente significativo, pero otros aspectos del desarrollo sí que lo son, como la decisión de encontrarse en secreto con el fin de consumar su deseo sexual ("concertaron, teniendo tiempo aparejado para ello, poner en effecto la execución de sus amo-

heridas y la sangre en esta obra, más allá de la conocida cita cervantina, cf. Martín Romero 2015b. 
res”, id.) y los obstáculos derivados de la existencia de un rival amoroso, en este caso don Rosanel. Este caballero salió una noche con una armadura distinta, para no ser reconocido, y se sentó escondido cerca de la ventana de Lupercia, con la esperanza de verla asomarse ${ }^{7}$. Aparece entonces Theobaldo, que canta a su dama mientras Rosanel es incómodo y mudo testigo del encuentro entre los amantes, quienes deciden verse un poco más tarde. Conviene señalar la originalidad de Antonio de Torquemada, que da la vuelta al motivo y propone un enfoque distinto, centrado no en el amante, sino en el personaje inoportuno. Rosanel, que se debate entre mantener el secreto o denunciar el hecho, decide finalmente no tomar cartas en el asunto, pero tanta dilación ha permitido que Theobaldo regresara para acudir a la cita de la dama. Un suspiro de Rosanel es oído por aquél, quien inmediatamente decide bajar (estaba ya subiendo por una escalera para llegar a la ventana de la habitación de su amada) y, a pesar de las negativas de Rosanel (a quien no reconoce), se produce finalmente una lucha entre ellos que termina con la muerte de Theobaldo a manos de su rival. Este personaje, como Florendos en Palmerín de Olivia, o Belianís en la obra homónima, se encuentra con un caballero que obstaculiza o molesta su cita amorosa. En este caso, no será el amante quien intente no ser reconocido e impedir la lucha, sino Rosanel, el caballero no correspondido, y será aquél quien lleve la peor parte, pues perecerá en el combate. Su muerte es distinta de la de Calisto, aunque en ambos casos se indica la herida craneal. Además, la situación en general coincide en diversos puntos, como en el encuentro erótico clandestino e ilícito entre los jóvenes, el ruido que lleva al amante a descender el muro de manera precipitada y la muerte de este caballero a causa de esas circunstancias, con mención expresa de la herida en la cabeza. Theobaldo muere a causa de ese encuentro ilícito y parece ser consciente de ello cuando exclama justo

7 "Y avino assí que una noche que Lupercia con Theobaldo tenía concertado de la manera que más a su voluntad le podría hablar, que era por una ventana baxa de su aposento que en un callejón angosto y sin salida que a las espaldas del palacio cerca del muro se hazía, don Rosanel, a quien el nuevo cuydado no dexava reposar como quisiera, armado de unas armas secretas con su espada y escudo disfraçado, que por ninguna vía podía ser conocido, se salió a passear por la ciudad de Brisea. Y como la noche hiziesse muy escura, a muy gran rato della se fue hazia aquella parte que diximos, pensando que Lupercia se pararía a la ventana" (TorQuEMADA 1997, p. 434). 
antes de morir: "¡Ay, mi señora Lupercia, que por vuestra causa soy muerto!” (1997, p. 436).

Por si fuera poco, la relación con La Celestina se hace aún más evidente en los hechos que suceden a continuación: Lupercia, tras la muerte de su amante, confiesa su culpa y expresa su deseo de suicidarse. Las palabras de esta dama recuerdan claramente las de Melibea: no sólo la confesión de su pecado y su deseo de morir, negándose a seguir con vida tras haber causado la muerte de su amigo, sino ideas más cercanas, como el anhelo de juntarse en la muerte con el amado y, lo que resulta más significativo, el deseo de imitar ("seguir") su suerte:

\section{La Celestina}

Pues, ¿qué crueldad sería, padre mío, muriendo él despeñado, que viviesse yo penada? Su muerte combida a la mía, combídame y fuerça que sea presto, sin dilación; muéstrame que ha de ser despeñada, por seguille en todo. No digan por mí "a muertos y a ydos..." (2001, pp. 600-601).

\section{Olivante de Laura}

No quiera Dios que en mí se sienta ingratitud de lo que devo a quien por mi causa recibió la muerte. Pues con otra cosa no puedo sacrificar que con más contentamiento dexe el ánima, que en la compañía del su Theobaldo quiere seguir su misma fortuna (1997, p. 437).

Lupercia, al igual que Melibea, se suicida arrojándose desde lo alto ("Y dicho esto, se echó de la ventana sin que ninguno pudiesse tenerla", $i d$.). Hay que recordar que precisamente este momento celestinesco fue visto por Beltrán Llavador (1994, p. 176) como huella del Tirant lo Blanc, cuando Carmesina, tras la muerte de este caballero, se expresa de forma parecida a Melibea: "Las palabras que lo expresan son las mismas: «Contentarle he en la muerte, pues no tuve tiempo en la vida» (auto $\mathrm{XX})$; «ab tu vull fer companyia en la mort, puix en la vida, que t'he tant amat, no t'he pogut servir» (c. 473)" ${ }^{8}$. Las similitudes entre el texto catalán y La Celestina en este punto ciertamente son notables. Pues bien, no resultan menos evidentes entre el texto de Rojas y el de Olivante de Laura. Podría pensarse aquí en una relación entre Tirante y Olivante, pero se ha de observar que el texto citado por Beltrán y el que aporto aquí son distin-

${ }^{8}$ En el texto de la traducción castellana anónima de 1516, que es el que quizá conoció Torquemada, la dama se expresa así: "Que ciertamente contigo quiero hazer compañía en la muerte, pues que en la vida, que tanto te amé, no te he podido servir" (Martorell y Galba 1974, t. 5, p. 196). 
tos pasajes del mismo momento de La Celestina. Si a eso añadimos el hecho de que Lupercia sí se suicida (lo que no hace Carmesina), al igual que Melibea (y de la misma forma), es fácil concluir que se trata de un recuerdo celestinesco y no procedente de Tirante.

Es más, la descripción de las consecuencias físicas del suicidio también recuerda a La Celestina; así, en Olivante de Laura, Lupercia, "dando con la cabeça en una piedra cerca de Theobaldo, dexó allí los sesos esparzidos, que no poco pesar causó en todos un caso tan desastrado" (Torquemada 1997, p. 437). La alusión a los "sesos esparzidos" de la dama evoca el comentario de Tristán a Sosia sobre los de Calisto tras morir: "Coge, Sosia, essos sesos de essos cantos; júntalos con la cabeza del desdichado amo nuestro" (Rojas 2001, pp. 586-587). Cierto es que aquí no son los del amante sino los de la amada, pero la imagen, tan fisiológicamente gráfica, coincide en ambas obras en situaciones hasta cierto punto paralelas. Curiosamente, en Primaleón, otro de los aspectos celestinescos (estudiados por Campos García Rojas 2013) es la relación entre Finea y Tarnaes, que termina con la muerte, primero, del joven y, posteriormente, de la dama, que se suicida como otra Melibea ante la ausencia de su amado. En Primaleón, la dama se suicida con una espada, una forma bien distinta a la escogida por Lupercia y por la amada de Calisto ${ }^{9}$. Ello pone de manifiesto que Torquemada quiso recordar, más claramente que su antecesor, esa huella de $L a$ Celestina, pues hizo que su personaje siguiera con mayor fidelidad el modelo de Melibea. Por tanto, también en Olivante de Laura descubrimos la evidencia de la conexión con el recuerdo celestinesco de este motivo que se encuentra en diversas obras caballerescas.

En definitiva, en los episodios que hemos analizado se detecta un motivo compuesto estructurado mediante la siguiente combinatoria de motivos simples:

1. Se fija una visita clandestina y nocturna (en ocasiones, con ventanas enrejadas o con escalas para ascender por el muro, como indicó Cervantes).

2. El caballero amante encuentra a otros caballeros que obstaculizan el encuentro,

9 Sobre el suicidio en los libros de caballerías, véanse CAmpos García Rojas 2001 y 2003 y MARTín Romero 2007, pp. 120-133; sobre el suicidio de Melibea, López-Ríos 2005. 
2.1. o bien antes de que se produzca,

2.2. o bien después de que se haya producido.

3. Ocasionalmente, se procede a disimular para no ser reconocido (suele ser el caballero amante, salvo en Olivante de Laura);

3.1. este caballero intenta evitar la lucha

3.2. e intenta no ser reconocido (no dice su nombre);

3.3. por ello, llega a veces a mudar la voz.

4. No obstante, se produce el enfrentamiento.

5. Uno de los caballeros resulta gravemente herido o incluso muerto (casi siempre el caballero inoportuno, salvo en Olivante de Laura).

Obsérvese que hay variantes sintagmáticas en los puntos 2, 3 y 5 . Además, en cuanto que el punto tercero no se da en algún caso, se obtendría, mediante la eliminación del enunciado tercero, un motivo más abstracto, pero que no negaría la existencia del motivo más concreto que incluyera dicho enunciado ${ }^{10}$. El tercero de los puntos no se da en Palmerín de Olivia. Se trata cronológicamente del primer libro de caballerías analizado, lo que lleva a pensar que ese momento de ocultación de identidad se incorporó posteriormente al desarrollo del motivo. El resto de las circunstancias del encuentro amoroso, la aparición de un personaje que supone un contratiempo y los riesgos derivados de esa situación, se da en todos los casos analizados. No sería extraño pensar que el recuerdo de la muerte de Calisto en una obra tan conocida hubiera inspirado la aparición de estos rasgos en los libros de caballerías, y que a partir de ese recuerdo se desarrollara el motivo del encuentro erótico clandestino -el motivo recordado por Cervantes- con ciertas peculiaridades (los rasgos que acabo de mencionar), de forma que, cada

10 Bueno Serrano explica que el "motivo sintagmático compuesto da cuenta de que a) las variantes se combinan formando otras más concretas y específicas, es decir, hay mayor longitud o extensión y menor concreción, y b) esta combinatoria es relevante porque cada uno de los enunciados que la integran entra también en combinación con otros en otros contextos, de modo que estos vienen a ser a su vez variantes. Así planteado, estamos de nuevo ante motivos pues trabajamos con 1) unidades narrativas y 2) recurrentes como paradigmas y como sintagmas" (2012, p. 96). Además, explica que "es una variante o concreción del motivo paradigmático y un motivo en sí mismo" (p. 95). Estoy de acuerdo con esta investigadora; efectivamente, se trata de una cuestión de enfoque, pues, teóricamente, un mismo motivo puede ser considerado de una u otra manera atendiendo a la estructura general en la que percibamos que se integra (y ello, además, variará de un texto a otro). 
vez que otro título lo retomaba, reforzaba, a su vez, su carácter de topos caballeresco.

En cualquier caso, no es de extrañar que los autores emplearan ese motivo con libertad. Como puede observarse, el episodio de Olivante de Laura sigue las pautas, pero invierte los papeles del caballero amante y del caballero que obstaculiza el encuentro. Ya he indicado que en Palmerín aún no se había incorporado el intento de ocultar la identidad ${ }^{11}$.

También en Leandro el Bel encontramos un episodio que guarda ciertas semejanzas con el esquema analizado, pero con algunas diferencias ${ }^{12}$. En el capítulo 44 se narra cómo el Caballero de Cupido, sobrenombre del protagonista del libro, ronda las cercanías de los aposentos de su amada princesa Cupidea para cantar y lamentar sus penas de amor: "Y lo más que hazía era irse cada noche a las espaldas del aposento de la princesa Cupidea, y allí cantando y lamentando manifestava su pena lo mejor que podía" (f. lvi); su rival amoroso, Floramor, con el sobrenombre de Caballero de las Doncellas, llega también al lugar: el mismo escenario nocturno, apartado y supuestamente desierto, como se ha visto en otros libros de caballerías ("una calleja que allí fasta a un lugar muy solitario donde por maravilla aportava gente", $i d$.), donde escucha al otro caballero suspirar y cantar a Cupidea; la letra de la canción no deja lugar a dudas a Floramor, que reconoce a Leandro el Bel y lo increpa considerando que es indigno de tal amor. Aquí, ni la noche ni la oscuridad ocultan las identidades: ambos se reconocen y comienzan a luchar en un combate que, lejos de mantenerse secreto, resulta en tanto estruendo que atrae a otros muchos guerreros, y la lid que sostenía un par de individuos se convierte en una reyerta que involucra un mayor número de combatientes, al punto de que varios de ellos mueren y la noticia llega a

11 Bueno Serrano recuerda el empleo libre al hablar de que los motivos "construyen el discurso caballeresco de ficción y contribuyen a su desarrollo, configurando en la práctica una poética proteica, dinámica, cíclica y múltiple con constantes y desvíos" (2012, p. 83). Esa libertad creativa de los autores frente a los modelos y motivos es precisamente uno de los grandes problemas a los que se enfrenta el estudioso de la literatura caballeresca. En ocasiones resulta más operativo indicar las variantes concretas de un determinado texto que eliminar de forma total del enunciado ciertas características sintagmáticas que son pertinentes.

12 Agradezco a Stefano Bazzaco y a Anna Bognolo que me indicaran que este episodio compartía ciertos rasgos con el motivo que estudiaba. Sobre Leandro el Bel, véase Bognolo 2008. 
oídos del emperador. No obstante, "ya los dos valientes cavalleros, tomando el cavallero de Cupido su laúd, se avían ido cada uno por su parte a sus posadas muy tristes" $(i d$.$) .$

Según puede comprobarse, también se encuentran en este episodio algunos de los rasgos del motivo analizado: las razones amorosas de un caballero para acercarse de noche, secretamente, a los aposentos de su amada, la aparición de un personaje inoportuno y la lucha que esto provoca, con los consecuentes peligros. Sin embargo, no encontramos aquí la cita amorosa (el amante se acerca a aliviar su pena, no para encontrarse con la dama); tampoco se produce la ocultación de identidades (aunque esto no se da en el episodio de Palmerín), pues ambos contendientes conocen a su rival; la resolución de la lucha, que implica una enorme revuelta, también es diferente (y, de nuevo, se parece más al episodio palmeriniano). Esto me sirve para señalar que la repetición de las circunstancias precisas del motivo analizado resulta más significativa de lo que pudiera pensarse y va mucho más allá de lo expresado por Cervantes y de la tradición cortés del secreto. El análisis más detenido de estos pasajes demuestra que, si de forma más abstracta es ostensible que la repetición de los lugares comunes apreciados por Cervantes es frecuente en bastantes libros de caballerías (y, como indicaré más adelante, no sólo en ellos), lo cierto es que se puede determinar la existencia de un motivo mucho más concreto, el que determino en el presente estudio apoyándome en la recurrencia de una serie de elementos y su aparición en un determinado orden.

Cabe pensar que este tipo de episodios es el resultado efectivo de la influencia de La Celestina y que, además, se convirtió en un motivo caballeresco más complejo que el del simple encuentro clandestino. No sería extraño que estos episodios hubieran influido, a su vez, en la forma como la ronda nocturna y sus peligros aparecen en la narrativa cortesana e incluso en el teatro áureo.

En este sentido, se ha de recordar El caballero de Olmedo de Lope de Vega, comedia en que localizamos la cita clandestina de los amantes, la aparición de hombres que obstaculizan el encuentro secreto, el enfrentamiento que de ello se deriva y la ocultación y confusión de identidades. En definitiva, descubrimos varios de los puntos del esquema del episodio analizado: recordemos que, efectivamente, en el acto I de esta comedia 1) se concierta una cita amorosa entre don Alonso y doña Inés, 
que, como las que Cervantes comentó en los libros de caballerías, es nocturna, clandestina y secreta, a las rejas de la casa de la dama; 2) cuando don Alonso llega a la hora indicada comprueba que en ese mismo lugar se encuentran dos hombres:

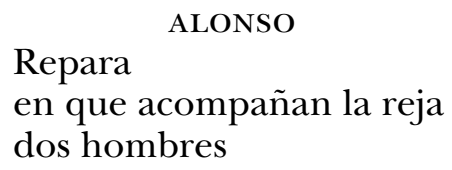

Se trata de don Rodrigo, también enamorado de doña Inés, y don Fernando, su amigo y amado de la hermana de esta dama; 3) don Alonso, que no revela su identidad, 4) los increpa y 5) surge un enfrentamiento (aunque limitado a lo verbal) que concluye con la marcha de los dos hombres, uno de los cuales pierde una capa (lo que indica que se fue con ciertas prisas), frente a don Alonso, quien decide no seguirlos. Se trata, de nuevo, del motivo del contratiempo peligroso de la cita secreta nocturna de los amantes.

Es cierto que hay diferencias: en primer lugar, no se produce la lucha, y, por tanto, no hay heridos (el peligro se queda en mero riesgo); además, doña Inés aún no sabe si su secreto amante es don Alonso, aunque lo intuye, y esa cita ha de servir para que ella salga de dudas (ha dejado una cinta que don Alonso deberá poner en su sombrero), aunque esto implicará un error de identificación que habrá de solventar finalmente Fabia, la alcahueta. Por lo demás, no se intenta disimular la propia identidad, aunque don Álvaro sí se niega a revelarla y se explicita que no se conocen; asimismo, el enfrentamiento no sobrepasa los límites verbales, pero la actitud de don Alonso se antoja bastante parecida a la de Belianís:

\author{
ALONSO \\ Hidalgos, \\ en las rejas de esa casa \\ nadie se arrima. \\ RODRIGO \\ ¿Qué es esto? \\ FERNANDO \\ Ni en el talle ni en el habla \\ conozco este hombre.
}




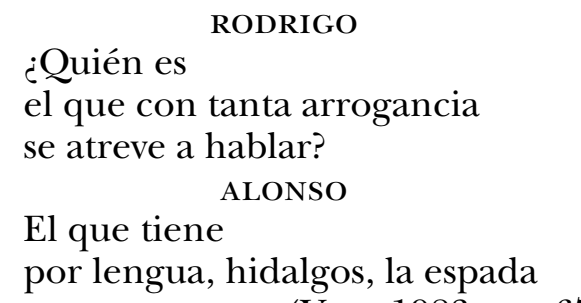

(Vega 1983, pp. 67-68).

Tanto don Alonso como Belianís ocultan su identidad y dejan traslucir el enfado ante quienes interrumpen su encuentro. Cierto es que don Alonso baraja la posibilidad de que haya sido la propia doña Inés quien lo ha engañado, pero ello no impide que este enfrentamiento en la comedia tenga reminiscencias de los que se producen en los episodios caballerescos citados. Por otra parte, aunque en la comedia de Lope de Vega don Alonso no intenta evitar la lucha, es cierto que decide no seguir a los inoportunos hidalgos y que oculta su identidad.

En su conjunto, este episodio recuerda más los libros de caballerías que el modelo celestinesco, si bien la influencia de Rojas en esta pieza resulta indiscutible, ya que en ella se alude en más de una ocasión a los personajes de La Celestina. Cuando Tello, criado de don Alonso, se dirige a Ana, criada de doña Inés, para que avise a su señora, se establece el siguiente diálogo:

TELLO

¿Está en casa Melibea?
Que viene Calisto aquí.
ANA
Aguarda un poco, Sempronio

Aguarda un poco,
(Vempronio 1983, p. 81).

Además, son numerosos los paralelismos entre la obra de Rojas y la comedia de Lope, fundamentalmente apoyados en la figura de Fabia, que ejerce como alcahueta, que se introduce en la casa de la dama como lo hizo el personaje de Rojas, que es recompensada con una cadena por sus gestiones de tercería y que se presenta como hechicera, con alusiones a la philocaptio ${ }^{13}$.

13 Sobre la influencia de La Celestina en Lope de Vega hay abundante bibliografía: Montesinos 1926; Oliver Asín 1928; NAgy 1968; Gutiérrez 1975; VÉlez-Quiñones 1993; Gómez 1998; Arellano 2001. 
Por tanto, esta evidente impronta celestinesca en El caballero de Olmedo-además de la aparición de la vieja hechicera y alcahueta, se observa en la relación de los amantes y los criados que parecen remedar a los de Calisto- pone de manifiesto que este motivo se vinculaba con la tradición originada por La Celestina, al tiempo que pertenecían a la tradición caballeresca.

No han de sorprender estas interferencias entre géneros tan distintos. El mismo Lope de Vega valoraba los vínculos entre la "novela" (entendida como novela corta) y la "comedia" cuando en sus Novelas a Marcia Leonarda afirmaba: "Demás que yo he pensado que tienen las novelas los mismos preceptos que las comedias" (Vega 2002, p. 183), si bien la opinión parecía reducirse a "haber dado su autor contento y gusto al pueblo, aunque se ahorque el arte" $(i d$.$) . No obstante, como han estu-$ diado Zimic (1975), Baquero Goyanes (1983), Jurado Santos (2000), Sánchez Martínez (2006) y, más recientemente, Fernández Rodríguez (2015) ${ }^{14}$, ambos géneros aparecían emparejados en la recepción de la época y existen numerosas interrelaciones entre ellos. Precisamente, estudiando la tipología de la ronda y el galanteo nocturnos, Profeti (2003, pp. 148-149) trae a colación los comentarios sobre La Celestina en Las fortunas de Diana, una de las Novelas a Marcia Leonarda, y recuerda la opinión citada anteriormente. Narrativa y teatro eran vistos como dos manifestaciones de un mismo fenómeno: la representación de una realidad ficticia, mediante la actuación en las tablas o en la construcción mental por medio de la palabra. No hay que olvidar que en las citadas Novelas a Marcia Leonarda Lope de Vega menciona los libros de caballerías en el mismo apartado de creación narrativa en el que se incluyen las novelas al modo italiano. Para Lope, entonces, el texto de Rojas forma parte, también, de ese mismo fenómeno de la representación de una realidad ficticia, al igual que las novelas italianas, los libros de caballerías o la novela griega. Son conocidos los trasvases argumentales entre novela y teatro, por ejemplo, desde las comedias caballerescas de Gil Vicente hasta las de Juan Pérez de Montalbán. La importancia de este grupo de obras dramáticas incide en el gusto por lo caballeresco y explica esa idea de vasos comunicantes entre géneros, en cuanto que eran vistos

14 Este último, centrándose en las comedias bizantinas y el modelo de la novela griega en Lope de Vega. Gómez (2017), en cambio, matiza acertadamente algunas de sus ideas. 
como formas distintas de un mismo hecho: la representación artística mediante la palabra ${ }^{15}$.

El fenómeno de la ronda se ha tratado en numerosos estudios, como el de Medina Suaheli (1998-1999), quien ha analizado el encuentro nocturno en el teatro de Lope de Vega y ha destacado la importancia de los "elementi di disturbo", entre los que indica el equívoco, el acompañante indeseado o la confusión de identidad (pp. 46-70), todo lo cual los acerca a ciertos rasgos de los episodios caballerescos ${ }^{16}$. La ronda también es el objeto de estudio del volumen colectivo coordinado por Castilla Pérez (2003); algunos de los artículos contenidos en este libro determinan ciertos detalles que coinciden en varios puntos con el motivo caballeresco analizado. Muñoz Palomares (2003, p. 284) habla de que la "reja y la oscuridad de la noche se convierten en el marco adecuado para los momentos más íntimos", y considera el balcón o la ventana como el "espacio para los encuentros secretos, las sutilezas y las pruebas de amor" (p. 289). El mismo investigador detecta que en la producción dramática este tipo de situaciones provoca "en no pocas ocasiones equívocos, confusiones de identidades, sospechas de deshonra y hasta desafíos" (p. 286). Por su parte, Agustín de la Granja (2003, p. 19) también indica que en el teatro áureo estas rondas nocturnas provocaban reyertas y peleas entre rivales amorosos. Como puede observarse, todos estos aspectos se encuentran ya en los libros de caballerías, incluso muchos fueron considerados como propiamente caballerescos en el Quijote:

Oyendo lo cual quedó don Quijote pasmado, porque en aquel instante se le vinieron a la memoria las infinitas aventuras semejantes a aquélla, de ventanas, rejas y jardines, músicas, requiebros y desvanecimientos que en los sus desvanecidos libros de caballerías había leído (Cervantes 2001, II, 44, p. 866).

Se trata de rasgos que, como se ha visto, forman parte del motivo analizado en el presente estudio.

Puede objetarse que todo ello se explica como resultado de diversas tradiciones literarias o del mismo folclore, por

15 Sobre el teatro caballeresco, véanse los numerosos estudios de Demattè $(2004,2007,2008,2010,2013)$, así como Demattè y Río NogueRAS 2012.

${ }_{16}$ Reitero mi agradecimiento a la gentileza de la profesora Anna Bognolo, por quien conocí este trabajo. 
no hablar de la propia realidad, pues la ronda nocturna y los encuentros secretos no eran infrecuentes en la época (Muñoz Palomares 2003, p. 294). Ahora bien, los paralelismos detectados y la reiteración de los rasgos indicados llevan a pensar que no nos encontramos ante un mero reflejo de una realidad concreta, que se repita porque se repite en la realidad, sino más bien ante una determinada manera literaria de representarla, una manera que se reconoce como topos literario, identificable por parte del público. La existencia de una tradición literaria más amplia (la ronda nocturna, las citas amorosas clandestinas) no explica por sí sola la aparición de un motivo mucho más preciso en su combinatoria, un motivo hasta ahora no determinado y que se vincula claramente con textos relacionados con $L a$ Celestina, aun cuando ese motivo, como tal, esté ausente en el texto de Rojas. Será en los libros de caballerías - precisamente en algunos en los que se detecta la huella celestinesca- donde se configure este motivo; su aparición en El caballero de Olmedo de Lope de Vega, que justamente se relaciona con La Celestina, apoya esta idea.

Sin duda, en la narrativa y el teatro del Siglo de Oro son numerosos los momentos de galanteo y ronda nocturna. Pero en este caso se trata de un episodio con un desarrollo concreto: no es cuestión de seducir, de galantear a la dama, sino de una cita concertada entre ambos que se ve obstaculizada por la presencia inoportuna de personajes inesperados. Esos otros personajes sí pueden pertenecer al ámbito de los que intentan rondar a la dama, pero en el motivo analizado el caballero no necesita hacer tales diligencias, pues ya ha conseguido que la mujer acepte el encuentro. Si se compara este episodio con otras entrevistas nocturnas en las comedias de Lope de Vega, donde no escasean, se evidencia que en este caso nos hallamos ante un desarrollo del motivo que no se da en las demás, un desarrollo que coincide con la estructura del motivo caballeresco. Sólo en El caballero de Olmedo se da la estructura que he determinado, lo que acerca la obra a los libros de caballerías.

Hasta el momento, estos elementos del teatro áureo habían sido estudiados al margen de la tradición caballeresca y, por tanto, del motivo que Cervantes estableció en el Quijote, cuando a todas luces resultan emparentados. El público de las comedias de Lope de Vega (y de otros ingenios áureos) estaba acostumbrado a este motivo caballeresco que hundía sus raíces en un momento concreto de La Celestina-que explicaba lo que pasa- 
ba por la cabeza de Calisto cuando decidió bajar apresuradamente. Debemos tener en cuenta que el público de la comedia lopesca conocía bien los libros de caballerías: no son pocos los de factura manuscrita que datan del siglo XVII, en cuya centuria se reeditó buen número de ellos; no son infrecuentes las apariciones de personajes caballerescos en desfiles y espectáculos de esos años. Además, la existencia de comedias caballerescas revela el gusto del público por este tipo de ficción. No se trata, entonces, de un género extinguido en esa época; el descenso de la producción impresa ha de tomarse en su justa medida. El éxito del Quijote demuestra por sí solo el interés por el género parodiado.

El encuentro nocturno obstaculizado aparece en El caballero de Olmedo sin olvidar los peligros cotidianos de esta circunstancia que quizá eran más habituales de lo que pudiera pensarse en la realidad de la época. Pues bien, ese mismo motivo en los libros de caballerías que he analizado es presentado igualmente con ese mismo toque de realismo (el mismo obstáculo puede ser visto como tal) o, mejor dicho, de verosimilitud que se apoya en la cotidianeidad.

No podemos olvidar que los libros de caballerías, sus personajes y sus episodios eran ampliamente conocidos y formaban parte de la sociedad del momento. Nadie era ajeno en esos años a ese tipo de literatura, por lo que intentar acercarse a las letras áureas ignorando ese caudal literario implica, cuando menos, una distorsión de la que debemos huir. La impronta de este género supera sus propios límites y alcanza toda la literatura (Martín Romero 2015a). Si los libros de caballerías configuraron la forma como los españoles que llegaban al Nuevo Mundo se acercaban a esa nueva realidad, que veían desde el prisma caballeresco (Leonard 1953), no es de extrañar que cualquier fenómeno literario se viera también sometido a ese prisma ofrecido por los libros de caballerías, ya que este género (el de mayor éxito de todo el Siglo de Oro) a buen seguro configuró también el modo de entender tanto cualquier producto literario como la misma percepción de la realidad.

En definitiva, existe el motivo del contratiempo peligroso de la cita secreta nocturna de los amantes, que no se da en La Celestina, pero guarda una clara relación con ella (no deja de ser la causa de la muerte de Calisto). Su configuración decisiva se produce en los libros de caballerías. El enorme éxito de los títulos que he estudiado, en los que se encuentra (y seguramente no sean los 
únicos), aseguró su difusión. Por último, su aparición en El caballero de Olmedo fuerza a entender este motivo como resultado de la influencia celestinesca -influencia aceptada por la crítica-, pero no como único recuerdo (no podía ser, porque en el texto de Rojas no aparece como tal), sino como eco también de la literatura caballeresca que todos los espectadores de la comedia conocían bien. Este motivo tiene su origen en la impronta del texto de Rojas sobre los libros de caballerías y fue precisamente en éstos donde se convirtió en motivo para ser retomado posteriormente por el teatro áureo y la narrativa cortesana.

\section{REFERENCIAS}

Alvar EzQuerra, Carlos (coord.) 2015. Estudios de literatura medieval en la Península Ibérica, Cilengua, San Millán de la Cogolla.

Arellano, Ignacio 2001. "La Celestina en la comedia del siglo xvii", en $L a$ Celestina. V Centenario (1499-1999). Actas del Congreso Internacional. Eds. Felipe Pedraza, Rafael Gómez Cañal y Gema Gómez Rubio, Universidad de Castilla-La Mancha, Cuenca, pp. 247-268.

Baquero Goyanes, Mariano 1983. "Comedia y novela en el siglo Xviı", en Serta philologica. F. Lázaro Carreter: natalem diem sexagesimum celebranti dicata, Cátedra, Madrid, t. 2, pp. 13-29.

Beltrán Llavador, Rafael 1988. "Paralelismos en los enamoramientos de Calisto y Tirant lo Blanc: los primeros síntomas del «mal del amar»", Celestinesca, 12, 2, pp. 33-53.

Beltrán Llavador, Rafael 1990. "Las «bodas sordas» en Tirant lo Blanc y la Celestina", Revista de Filología Española, 70, pp. 91-117.

Beltrán Llavador, Rafael 1990a. "Eliseu (Tirant lo Blanc) a l'espill de Lucrecia (la Celestina): retrat de la donzella com a complice fidel de l'amor secret", en Miscel.lània Joan Fuster. Eds. A. Ferrando y A. Hauf, Publicacions de l'Abadia de Montserrat, Barcelona, t. 1, pp. 95-124.

Beltrán Llavador, Rafael 1991. "Relaciones de complicidad en el juego amoroso: Amadis, Tirant, y La Celestina", en Evolución narrativa e ideológica de la literatura caballeresca. Ed. M. Eugenia Lacarra, Universidad del País Vasco-EHU, Vitoria, pp. 103-126.

Beltrán Llavador, Rafael 1994. "La huella de Tirant lo Blanc en la Celestina”, en Actas del III Congreso de la Asociación Hispánica de Literatura Medieval. Ed. M. Isabel Toro Pascua, Universidad de Salamanca, Salamanca, t. 1, pp. 169-179.

Beysterveldt, Antony van 1982. Amadís-Esplandián-Calisto: historia de un linaje adulterado, J. Porrúa Turanzas, Madrid.

Blay Manzanera, Vicenta 1998. "La convergencia de lo caballeresco y lo sentimental", en Literatura de caballerias y origenes de la novela. Ed. Rafael Beltrán, Universitat de València, València, pp. 259-287.

Bognolo, Anna 2008. Leandro el Bel (guía de lectura), Centro de Estudios Cervantinos, Alcalá de Henares. 
Brandenberger, Tobias 2012. La muerte de la ficción sentimental. Transformaciones de un género iberorrománico, Verbum, Madrid.

Bueno Serrano, Ana Carmen 2007. "Aproximación al estudio de los motivos literarios en los libros de caballerías castellanos (1508-1516)", en De la literatura caballeresca al "Quijote". Coord. Juan Manuel Cacho Blecua. Eds. Ana Carmen Bueno Serrano, Patricia Esteban Erlés y Karla Xiomara Luna Mariscal, Prensas Universitarias de Zaragoza, Zaragoza, pp. 95-114.

Bueno Serrano, Ana Carmen 2012. "Motivos folclóricos y caballerescos en los libros de caballerías castellanos”, Revista de Poética Medieval, 26, pp. 83-108.

Cacho Blecua, Juan Manuel 2012. "El motivo en la literatura caballeresca. Presentación”, Revista de Poética Medieval, 26, pp. 11-30.

CAmpos García Rojas, Axayácatl 2001. "Formas y estrategias de la persuasión en la narrativa medieval hispánica: consejos y suicidios en los libros de caballerías", Revista de Poética Medieval, 6, pp. 11-26.

Campos García Rojas, Axayácatl 2003. "El suicidio en los libros de caballerías castellanos", en Propuestas teórico-metodológicas para el estudio de la literatura hispánica medieval. Ed. Lillian von der Walde Moheno, Universidad Nacional Autónoma de México- Universidad Autónoma Metropolitana, México, pp. 387-415.

Campos García Rojas, Axayácatl 2013. "Ecos de La Celestina en el Primaleón: objetos mágicos y prendas de amor”, Celestinesca, 37, pp. 9-26.

Castilla Pérez, Roberto 2003. Ronda, cortejo y galanteo en el teatro español del Siglo de Oro, Universidad de Granada, Granada.

Castro, Álvaro de 2000. Libro segundo de Clarián de Landanís. Ed. Javier Guijarro Ceballos, Centro de Estudios Cervantinos, Alcalá de Henares.

Cervantes SaAvedra, Miguel de 2001. El ingenioso hidalgo don Quijote de la Mancha. Edición IV centenario. Ed. Diego de Clemencín. Est. prel. de Luis Astrana Marín, Editorial Alfredo Ortells, Madrid.

Clemencín, Diego 2001. "Comentarios al Quijote", en El ingenioso hidalgo don Quijote de la Mancha. Edición IV centenario, Editorial Alfredo Ortells, Madrid, pp. 990-1977.

Cravens, Sydney Paul 2000. "Amadís de Gaula reivindicado por Feliciano de Silva”, Nueva Revista de Filología Hispánica, 48, 1, pp. 51-69.

Demattè, Claudia 2004. "El teatro caballeresco del siglo XVII: hacia una clasificación de las dinámicas transtextuales", en Actas del XIV Congreso de la Asociación Internacional de Hispanistas: New York, 16-21 de julio de 2001. T. 2: Literatura española, siglos XVI y XVII. Coords. Isaías Lerner, Roberto Nival y Alejandro Alonso, Juan de la Cuesta, Newark, pp. 181-186.

Demattè, Claudia 2007. "Teatro caballeresco y segundones. Crónica de una pasión no sólo literaria por los libros de caballerías", en Los segundones, importancia y valor de su presencia en el teatro aurisecular: actas del congreso internacional (Gargnano del Garda, 18-21 de septiembre de 2005). Coords. Alessandro Cassol y Blanca Oteiza Pérez, Iberoamericana-Vervuert, Madrid-Frankfurt/M., pp. 61-73.

Demattè, Claudia 2008. "Del libro a las tablas: la comedia Las aventuras de Grecia como ejemplo de reescritura burlesca de la materia caballeresca”, en Amadís de Gaula quinientos años después. Estudios en homenaje a Juan Manuel Cacho Blecua. Coords. José Manuel Lucía Megías, María Carmen 
Marín Pina y Ana Carmen Bueno Serrano, Centro de Estudios Cervantinos, Alcalá de Henares, pp. 175-190.

Demattè, Claudia 2010. "El proyecto «Un autor madrileño recuperado: Juan Pérez de Montalbán»", en Cuatrocientos años del "Arte nuevo de hacer comedias" de Lope de Vega. Actas selectas del XIV Congreso de la Asociación Internacional de Teatro Español y Novohispano de los Siglos de Oro: Olmedo, 20 al 23 de julio de 2009. Coords. Germán Vega García-Luengos y Héctor Urzáiz Tortajada, Universidad de Valladolid, Valladolid, t. 2, pp. 401-407.

Demattè, Claudia 2013. "La fama en la parodia: Juan Pérez de Montalbán y sus reescritores burlescos", en Comedia burlesca y teatro breve del Siglo de Oro. Coords. Alain Bègue, Carlos Mata Induráin y Pietro Taravacci, Ediciones de la Universidad de Navarra, Pamplona, pp. 129-142.

Demattè, Claudia 2015. "Hacia la edición de la obra completa de Juan Pérez de Montalbán: el «Primer tomo de comedias» (1635)”, en El patrimonio del teatro clásico español: actualidad y perspectivas. Homenaje a Francisco Ruiz Ramón: actas selectas del Congreso del TC/12 Olmedo, 22 al 25 de julio de 2013. Coords. Germán Vega García-Luengos, Héctor Urzáiz Tortajada y Pedro Conde Parrado, Universidad de Valladolid, Valladolid, pp. 291-298.

Demattè, Claudia y Alberto del Río Nogueras 2012. Parodia de la materia caballeresca y teatro áureo. Edición de "Las aventuras de Grecia" y su modelo serio, el "Don Florisel de Niquea" de Montalbán, GRISO-Universidad de Navarra, Pamplona. (Biblioteca Áurea Digital, 12).

Deyermond, Alan D. 1993. "Las relaciones genéricas de la ficción sentimental”, en Tradiciones y puntos de vista en la ficción sentimental, Universidad Nacional Autónoma de México, México, pp. 43-64.

Fernández, Jerónimo 1997. Belianis de Grecia. Ed. Lilia E.F. de Orduna, Reichenberger, Kassel, 2 ts.

Fernández Rodríguez, Daniel 2015. "Las técnicas y artificios de la novela griega y las comedias bizantinas de Lope", en Venia docendi. Actas del IV Congreso Internacional Jóvenes Investigadores Siglo de Oro (JISO 2014). Eds. C. Mata y A. Zúñiga, Universidad de Navarra, Pamplona, pp. 61-71.

Garza Merino, Sonia 1998. Amadís de Gaula (libro I). Motivos y unidades narrativas, tesis, Departamento de Filología, Alcalá de Henares.

Gómez, Jesús 1990. "Las «Artes de amores», «Celestina», y el género literario de la «Penitencia de amor» de Urrea", Celestinesca, 14, 1, pp. 3-16.

Gómez, Jesús 1998. "Primeros ecos de Celestina en las comedias de Lope", Celestinesca, 22, 1, pp. 3-42.

Gómez, Jesús 2017. "El «artificio griego» en Lope de Vega: narrativa y teatro", Anuario Lope de Vega. Texto, Literatura, Cultura, 23, pp. 441-460.

González Gonzalo, Antonio JoaQuín 2002-2003. "Un ejemplo de tercería cortesana: Celacunda (Clarián de Landanis. Gabriel Velázquez de Castillo. 1518)”, Angélica. Revista de Literatura, 11, pp. 67-96.

González Gonzalo, ANTONio JoaQuín 2005. "Introducción" a su edición de Clarián de Landanis. (Libro Primero), Centro de Estudios Cervantinos, Alcalá de Henares.

Granja, Agustín de la 2003. "Ronda y galanteo en la España del Siglo de Oro", en Ronda, cortejo y galanteo en el teatro español del Siglo de Oro. Ed. Roberto Castilla Pérez, Universidad de Granada, Granada, pp. 11-28. 
Guijarro Ceballos, Javier 1999. El "Floriseo" de Fernando Bernal, Editora Regional de Extremadura, Mérida.

Guijarro Ceballos, Javier 2000. "Introducción” a su ed. de Álvaro de Castro, Libro segundo de Clarián de Landanís, Centro de Estudios Cervantinos, Alcalá de Henares, pp. ix-xxx.

Guijarro Ceballos, Javier 2001. "La Celestina y el Libro segundo de don Clarián de Álvaro de Castro”, Laurel, 3, pp. 5-36.

Guijarro Ceballos, Javier 2002. "El ciclo de Clarián de Landanís [15181522-1524-1550]", Edad de Oro, 21, pp. 251-269.

Gutiérrez, V. 1975. "La Celestina en las comedias de Lope de Vega", Explicación de Textos Literarios, 4, pp. 161-168.

INFANTES, Víctor 1989. "La prosa de ficción renacentista: entre los géneros editoriales y el «género editorial»", Journal of Hispanic Philology, 13, pp. 115-124.

Jurado Santos, Agapita 2000. "Lope, Cervantes y La ilustre fregona", en "Otro Lope no ha de haber". Atti del convegno internazionale su Lope de Vega, 10-13 frebbraio 1999. Ed. Maria Grazia Profeti, Atesa, Firenze, t. 3, pp. 63-83.

LACARra LANz, Eukene 1989. "La parodia de la ficción sentimental en la Celestina", Celestinesca, 13, 1, pp. 11-30.

Leandro el Bel [después de 1582]. Francisco Pérez, Sevilla, ejemplar Viena: Nationalbibliothek, 40.R.27/2.

Leonard, Irving Albert 1953. Los libros del conquistador, Fondo de Cultura Económica, México.

Lida de Malkiel, María Rosa 1962. La originalidad artística de la Celestina, EUDEBA, Buenos Aires.

López-Ríos Moreno, Santiago 2005. “«Pon tú en cobro este cuerpo que allá baja»: Melibea y la muerte infamante en la Celestina”, en Dejar hablar a los textos. Homenaje a Francisco Márquez Villanueva. Coord. Pedro Manuel Piñero Ramírez, Universidad de Sevilla, Sevilla, t. 1, pp. 309-330.

Lucía Megías, José Manuel 2002. "Libros de caballerías castellanos. Textos y contextos", Edad de Oro, 21, pp. 9-60.

Lucía Megías, José Manuel y Emilio José Sales Dasí 2002. "La otra realidad social en los libros de caballerías castellanos. 1. Los enanos", Rivista di Filología e Letterature Ispaniche, 5, pp. 9-23.

Lucía Megías, José Manuel y Emilio José Sales Dasí 2005. "La otra realidad social en los libros de caballerías (II): damas y doncellas lascivas", en Actes del X Congrés Internacional de l'Associació Hispànica de Literatura Medieval: Alicante, 16-20 de septiembre de 2003. Coords. Josep Lluís Martos Sánchez, Josep Miquel Manzanaro i Blasco y Rafael Alemany Ferrer, Institut Interuniversitari de Filologia Valenciana, Alacant, t. 2, pp. 1007-1022.

Lucía Megías, José Manuel y Emilio José Sales Dasí 2007. "La otra realidad social en los libros de caballerías. III. El caballero «anciano»", en Actas del XI Congreso Internacional de la Asociación Hispánica de Literatura Medieval (Universidad de León, 20 al 24 de septiembre de 2005). Coords. Armando López Castro y María Luzdivina Cuesta Torre, Universidad de León, León, t. 2, pp. 783-795.

Lucía Megías, José Manuel y Emilio José Sales Dasí 2009. "La otra realidad social en los libros de caballerías: IV. De los «desamorados» a los adúlteros", en Medievalismo en Extremadura. Estudios sobre literatura y 
cultura hispánicas de la Edad Media. Coords. Jesús Cañas Murillo, Francisco Javier Grande Quejigo y José Roso Díaz, Universidad de Extremadura, Cáceres, pp. 527-544.

Luna Mariscal, Karla Xiomara 2007. "Índice de motivos de las historias caballerescas del siglo xvi: catalogación y estudio”, en De la literatura caballeresca al "Quijote". Coord. Juan Manuel Cacho Blecua. Eds. Ana Carmen Bueno Serrano, Patricia Esteban Erlés y Karla Xiomara Luna Mariscal, Prensas Universitarias de Zaragoza, Zaragoza, pp. 347-359.

Luna Mariscal, Karla Xiomara 2008. "Aproximación al estudio de las historias caballerescas breves a partir de los motivos folclóricos", en Amadís de Gaula: quinientos años después. Estudios en homenaje a Juan Manuel Cacho Blecua. Eds. José Manuel Lucía Megías y María Carmen Marín Pina. Col. Ana Carmen Bueno, Centro de Estudios Cervantinos, Alcalá de Henares, pp. 457-469.

Luna Mariscal, Karla Xiomara 2010. "Problemas teóricos y metodológicos en la elaboración de un índice de motivos folclóricos de las historias caballerescas del siglo Xvi", en Expresiones de la cultura y el pensamiento medievales. Eds. Lillian von der Walde Moheno, Concepción Company y Aurelio González, El Colegio de México-Universidad Nacional Autónoma de México-Universidad Autónoma Metropolitana, México, pp. 313-325.

Luna Mariscal, Karla Xiomara 2010a. "De la metodología o la pragmática del motivo en el índice de motivos de las historias caballerescas breves", eHumanista, 16, pp. 127-135.

Luna Mariscal, Karla Xiomara 2013. Índice de motivos de las Historias caballerescas breves. Motivos. Novelas. Concordancias, Academia del Hispanismo, Vigo.

Marín Pina, M. Carmen 2008. "Los libros de caballerías castellanos", en Amadis de Gaula, 1508: quinientos años de libros de caballerías. [Madrid, 9 de octubre de 2008 a 19 de enero de 2009], Biblioteca Nacional de EspañaSociedad Estatal de Conmemoraciones Culturales, Madrid, pp. 165-190.

Martín Romero, José Julio 2004. "Garcilaso como objeto de imitación poética y de reescritura narrativa”, en Memoria de la palabra. Actas del VI Congreso de la Asociación Internacional Siglo de Oro, Burgos-La Rioja 15-19 de julio 2002. Coords. Francisco Domínguez Matito y María Luisa Lobato López, Iberoamericana-Vervuert, Madrid-Frankfurt/M., t. 2, pp. 1267-1275.

Martín Romero, José Julio 2007. Entre el Renacimiento y el Barroco. Pedro de la Sierra y su obra, Prensas Universitarias de Zaragoza, Zaragoza.

Martín Romero, José Julio 2010. "Fidelidad sentimental y catarsis amorosa en el ciclo de Amadís de Gaula", Revista de Literatura Medieval, 22, pp. 155-184.

Martín Romero, José Julio 2014. "Palmerín de Olivia como enmienda del modelo amadisiano: el rechazo de la perfección arquetípica", Revista de literatura, 76, 152, pp. 425-445.

Martín Romero, José Julio 2015. "Psicología, pragmatismo y motivaciones encubiertas en el universo caballeresco de Palmerín de Olivia", en Estudios de literatura medieval en la Península Ibérica. Coord. Carlos Alvar Ezquerra, Cilengua, San Millán de la Cogolla, pp. 941-954. 
Martín Romero, José Julio 2015a. "La influencia de los libros de caballerías en las obras cervantinas sobre el cautiverio", Nueva Revista de Filología Hispánica, 63, 2, pp. 371-397.

Martín Romero, José Julio 2015b. "Heridas, sangre y cicatrices en Belianís de Grecia. Las proezas de un héroe herido", en Literatura y ficción: "estorias”, aventuras y poesía en la Edad Media. Coord. Marta Haro Cortés, Universitat de València, València, t. 2, pp. 563-577.

Martín Romero, José Julio 2015c. La guerra en la literatura castellana del siglo $X V$, Queen Mary and Westfield College, London.

Martín Romero, José Julio 2016. "La honra femenina en la literatura caballeresca”, en Antes se agotan la mano y la pluma que su historia = Magis déficit manus et calamus quam eius historia. Homenaje a Carlos Alvar. Coords. Constance Carta, Sarah Finci y Dora Mancheva, Cilengua, San Millán de la Cogolla, t. 2, pp. 1557-1576.

Martorell, Johnot y Martí Joan de Galba 1974. Tirante el Blanco. Versión castellana impresa en Valladolid en 1511. Ed., intr. y notas de Martín de Riquer, Espasa-Calpe, Madrid, 5 ts.

Medina, SuAheli 1998-1998. L'incontro clandestino notturno nel teatro di Lope de Vega, tesi di laurea, Università di Pisa.

Montesinos, José F. 1926. "Dos reminiscencias de La Celestina en el teatro de Lope", Revista de Filología Española, 13, pp. 60-62.

Muñoz Palomares, ANTONio 2003. "El ventanear y otras prácticas de galanteo en el teatro de Mira de Amescua", en Ronda, cortejo y galanteo en el teatro español del Siglo de Oro. Ed. Roberto Castilla Pérez, Universidad de Granada, Granada, pp. 277-299.

NaGy, E. 1968. Lope de Vega y "La Celestina”, Universidad Veracruzana, México.

Oliver Asín, J. 1928. "Más reminiscencias de La Celestina en el teatro de Lope”, Revista de Filología Española, 15, pp. 67-74.

Palmerín de Olivia 2004. Ed. Giuseppe di Stefano. Rev. de Daniela Pierucci. Introd. de M. Carmen Marín Pina, Centro de Estudios Cervantinos, Alcalá de Henares.

Profeti, Maria Grazia 2003. "Ronda, cortejo y galanteo: tipologías de Lope”, en Ronda, cortejo y galanteo en el teatro español del Siglo de Oro. Ed. Roberto Castilla Pérez, Universidad de Granada, Granada, pp. 135-149.

Riquer, Martín de 1973. "Cervantes y la caballeresca", Suma cervantina, Tamesis, London, pp. 273-298.

Rodríguez de Montalvo, Garci 1991. Amadís de Gaula. Ed. Juan Manuel Cacho Blecua, Cátedra, Madrid, 2 ts.

Rojas, Fernando de 2001. La Celestina o comedia o tragicomedia de Calisto y Melibea. Ed. Peter E. Russell, Castalia, Madrid.

Sales Dasí, Emilio J. 2000. "Ecos celestinescos en el Lisuarte de Grecia de Feliciano de Silva", Tirant. Butlleti Informatiu i Bibliogràfic, 3, http:/ / parnaseo.uv.es/ Tirant/ Art.Sales_ecos.htm [consultado el 10 de octubre de 2016].

Sales Dasí, Emilio J. 2001. "Feliciano de Silva, aventajado «continuador» de Amadises y Celestinas", en La Celestina, V centenario (1499-1999). Actas del congreso internacional Salamanca, Talavera de la Reina, Toledo, La Puebla de Montalbán, 27 de septiembre-1 de octubre de 1999. Coords. Felipe B. 
Pedraza Jiménez, Gemma Gómez Rubio y Rafael González Cañal, Ediciones de la Universidad de Castilla-La Mancha, Cuenca, pp. 403-414.

SÁnchez Martínez, Rafael 2006. "El teatro en el arte narrativo de Lope de Vega”, Tonos Digital. Revista de Estudios Filológicos, 12, https:/ /www.um.es/ tonosdigital/ znum12/ secciones/ Estudios\%20V-Lope\%20de\%20Vega. htm\#_ftn5 [consultado el 10 de octubre de 2016].

Sarmatti, Elisabetta 1996. Le critiche ai libri di Cavalleria nel Cinquecento spagnolo (con uno sguardo sul seicento). Un'analisi testuale, Giardini, Pisa.

Severin, Dorothy Sherman 1984. "La parodia del amor cortés en La Celestina”, Edad de Oro, 3, pp. 275-280.

Sharrer, Harvey L. 1984. "La fusión de la novela artúrica y sentimental a fines de la Edad Media”, El Crotalón. Anuario de Filología Española, 1, pp. 147-157.

SPINELLi E. 1983-1984. "Chivalry and its terminology in the Spanish sentimental romance", La Corónica, 12, pp. 241-253.

Torquemada, Antonio de 1997. Don Olivante de Laura. Ed. Isabel Muguruza, Biblioteca José Antonio de Castro, Madrid.

VEGA, Lope DE 1983. El caballero de Olmedo. Ed. Joseph Pérez, Castalia, Madrid.

VegA, Lope De 2002. Novelas a Marcia Leonarda. Ed. Antonio Carreño, Cátedra, Madrid.

Velázquez del Castillo, Gabriel 2005. Clarián de Landanís. (Libro primero). Ed. Antonio Joaquín González Gonzalo, Centro de Estudios Cervantinos, Alcalá de Henares.

Vélez-Quiñones, Harry 1994. La celestinesca, la comedia y "La Dorotea": huellas $e$ intertextos, Universidad de Salamanca, Salamanca.

Zimic, Stanislav 1975. "Francisco de Quintana, un novelista olvidado, amigo de Lope de Vega”, Boletín de la Biblioteca Menéndez Pelayo, 51, pp. 169-232. 